\title{
New phenotypic typing scheme for group B streptococci
}

\author{
S R Heard, J A Mawn
}

\begin{abstract}
Aims: To develop a new typing system for group B streptococci based on ${ }^{35}$ S-methionine-labelled protein profiles of bacterial proteins.

Methods: 377 clinical isolates of group B streptococci were examined by incorporation of ${ }^{35}$ S-methionine into bacterial proteins under strict anaerobic conditions. After sodium dodecylsulphatepolyacrylamide gel electrophoresis, autoradiography was performed. The patterns produced were visually analysed and categorised into clusters of organisms based on the pattern of band production between 32-46 kilodaltons.

Results: 294 of the typed strains classified into seven different groups designated ag. 32 strains failed to incorporate ${ }^{35} \mathrm{~S}$ methionine sufficiently to be grouped and 11 strains did not fall into one of the seven identified groups. Typability, reproducibility, and discrimination of the system was evident.

Conclusions: This typing system may help to distinguish between colonising and invasive strains of the organism.
\end{abstract}

(F Clin Pathol 1993;46:145-148)

Group B streptococci are commensals of the gastrointestinal and female genital tracts. Up to $28 \%$ of pregnant women may carry this organism in the vagina. ${ }^{1}$ It is an important neonatal pathogen, responsible for both early and late onset neonatal sepsis which is characterised by a potentially life-threatening pneumonia, septicaemia, or meningitis. The incidence of neonatal disease varies, with two to three cases per 1000 live births being reported from the United States ${ }^{23}$ and 0.3 per 1000 live births in the United Kingdom. ${ }^{4}$ Prematurity and low birthweight, prolonged rupture of membranes, and maternal pyrexia are recognised as important risk factors in susceptible mother-infant pairs. ${ }^{5}$ Maternal sepsis accounts for $10-20 \%$ of septicaemias after delivery in the United States: group B streptococci is the second most common blood culture isolate in this setting. ${ }^{6}$ The pathogenesis of early onset neonatal disease is related to the degree of genital colonisation in the mother $^{7}$ which may be reduced by prophylaxis with chlorhexidene during delivery, ${ }^{8}$ and to additional risk factors which contribute to the potential for the organism to cause invasive disease. ${ }^{9}$ The epidemiology of late onset disease is less well defined but both maternal and nosocomial sources have been implicated. ${ }^{10}$ Cross-infection resulting in nosocomial outbreaks in nurseries has also been well documented. ${ }^{11}$

Current typing methods for the organism are based on a reference laboratory typing scheme using serotyping followed, if necessary, by phage typing. This combined approach may be required because although most clinical strains can be serotyped, this system lacks sufficient discrimination, and less than $80 \%$ of strains can be typed using bacteriophages alone. ${ }^{12}$ Serological classification is based on Lancefield's original description of two cell wall carbohydrate antigens, the group specific common antigen carried by all strains, and the type specific capsular antigen. Clinical strains are currently divided serologically according to the presence of specific antigen into seven groups (Ia, Ib, Ia/c, II, III, IV, VI).$^{13}$ Groups I, II, and III are associated with early onset neonatal disease, while type III causes $90 \%$ of all cases of both early and late onset meningitis and $90 \%$ of all cases of late onset disease..$^{14}$ In addition to the polysaccharide antigens, $C$ proteins on the surface of group B streptococci form a complex composed of at least four different components $(a, \beta, \gamma$ and $\delta$ ) which are found on all $\mathrm{Ib}$ strains and in up to two thirds of type II and III strains. ${ }^{15}$ Additional protein antigens, termed $\mathbf{R}$ and $\mathrm{X}$, have also been described. These are primarily associated with type II and III strains. ${ }^{16}$ An epidemiological study using restriction endonuclease analysis has recently demonstrated the usefulness of this technique in examining recurrent invasive disease $^{17}$ and in outbreaks, ${ }^{18}$ but it has not been formulated into a typing system.

Neither serological nor phage typing systems can distinguish between colonising strains and those which have the potential to cause invasive disease in neonates. It is clear that host immunological factors, including the amount of type specific protective antibody that is present, are of critical importance in the development of invasive disease, ${ }^{19}$ but pathogenic factors related to particular strains of invasive organisms are still not well defined.

We were specifically interested in investigating the role of bacterial proteins in strain speciation as there is evidence that at least the $\mathrm{C}$ protein is a likely virulence factor and may, in fact, be a potentially good candidate for a vaccine. ${ }^{152021}$ The immunological study of the disease has certainly identified one aspect of 
invasive disease, but it may be that characteristics of the organism itself can account, in part, for its clinical behaviour. To date, serological, phage, and molecular attempts at classification systems have failed to be of benefit in identifying potentially "high-risk" invasive strains. The typing system presented here attempts to classify the organism at the phenotypic level and is based on the development of a typing scheme using ${ }^{35} \mathrm{~S}$-methionine incorporation into bacterial proteins.

\begin{abstract}
Methods
Sequential group B streptococci isolates grown under standard laboratory conditions from high vaginal swabs received in the clinical laboratory were purified and stored in glycerol broth at $-70^{\circ} \mathrm{C}$. After detailed experimental conditions for the optimal incorporation of ${ }^{35} \mathrm{~S}$-methionine into group B streptococci had been ascertained, the most important of which is the requirement for strict anaerobic conditions, the stored strains were inoculated on to pre-reduced blood agar and Islam's media (Oxoid, Basingstoke) and were incubated in an anaerobic chamber $\left(10 \% \mathrm{H}_{2}, 10 \% \mathrm{CO}_{2}, 80 \% \mathrm{~N}_{2}\right.$; Don Whitley Instrumentation) for 24 hours. ${ }^{35} \mathrm{~S}$-methionine (Amersham International) at a final concentration of $10 \mu \mathrm{Ci}$ was added to $100 \mu \mathrm{l}$
\end{abstract}

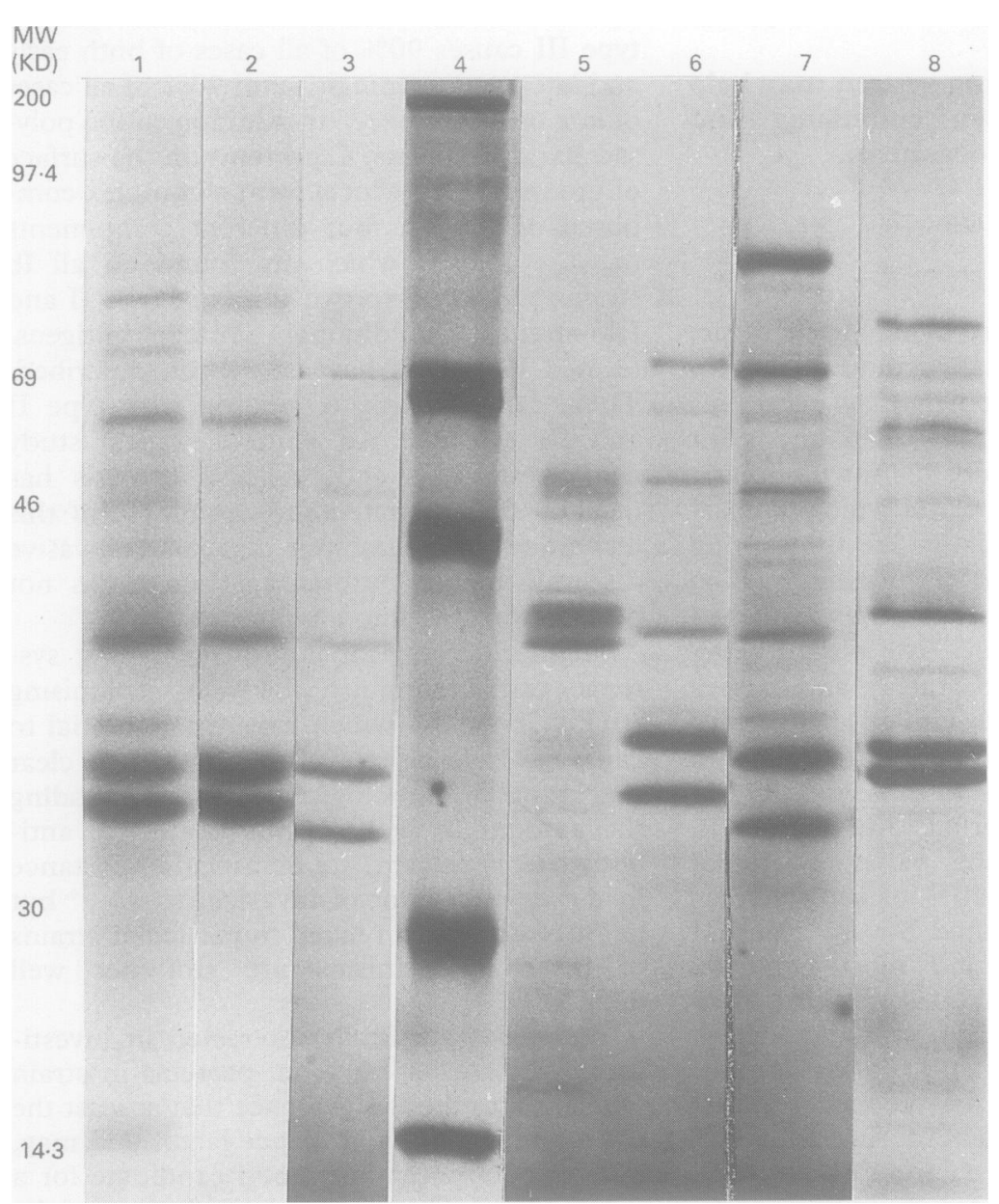

Figure 1 Autoradiographs of seven standard strains of group B streptococci. Lanes 1-3: strains $a, b, c$; lane 4: molecular weight markers; lanes 5-8: strains d, e, $f, g$. aliquots of sterile pre-reduced methionine free modified Eagle's medium (Flow Laboratories) which was inoculated with a standard loop of group B streptococci calculated to $20 \mu \mathrm{g}$ of protein. The mixture was then incubated for two to eight hours at $37^{\circ} \mathrm{C}$ under strict anaerobic conditions. An equal volume of double strength cracking buffer (2\% 2-mercaptoethanol, $20 \%$ sodium dodecylsulphate (SDS), and $40 \%$ glycerol) was then added to stop the incorporation. After boiling for 5 minutes and cooling, $35 \mu \mathrm{l} \mathrm{sam-}$ ples were loaded into sample lanes of a $4 \%$ stacking gel and electrophoresed into a $10 \%$ SDS-acrylamide (BDH Laboratories) resolving gel. ${ }^{14} \mathrm{C}$-methylated molecular weight markers (Range: $14 \cdot 3-200$ kilodaltons) to a final activity of $0.1 \mu \mathrm{Ci}$ were run with each gel, and as the system became clarified, appropriate specific controls were also used. Eight standard NCTC strains were also analysed using this typing methodology. Twenty five per cent of the strains were typed between two and four times to assess the reproducibility of the method.

Electrophoresis was performed using a Protean II dual vertical slab gel with $16 \mathrm{~cm}$ plates (Biorad Laboratories, Richmond, California) at $4^{\circ} \mathrm{C}$. A constant current of 35 $\mathrm{mA}$ was applied to run the samples through the stacking gel, after which the current was increased to $55 \mathrm{~mA}$ for 3-4 hours. The gels were fixed $(10 \%$ acetic acid, $10 \%$ isopropanol), dried, and autoradiographed. Analysis of the autoradiographs was performed independently by two researchers (SRH and JM) by visual analysis of the bands which were within the molecular weight range 30-46 kilodaltons.

\section{Results}

Three hundred and thirty seven strains were studied. A comparative visual analysis of the bands in the molecular weight range 30-46 kilodaltons showed that $294(87 \%)$ of strains could be classified into seven groups designated a-g. Consideration of bands above or below this region complicated the classification and did not contribute to reliable discrimination among strains. Thirty two strains (9\%) failed to incorporate the ${ }^{35} \mathrm{~S}$-methionine sufficiently to be grouped and 11 strains could not be classified into one of the seven groups. The 73 strains typed on more than one occasion gave the same result each time.

The groups distinguished by a distinctive pattern on ${ }^{35} \mathrm{~S}$-methionine protein analysis are designated as $a, b, c, d, e, f$ and $g$. Autoradiographs showing these seven groups are shown in fig 1 . The distribution of the 294 typed strains within the seven strains is shown in the table. Figure 2 comprises autoradiographs of eight standard NCTC serotyped strains of group B streptococci. These show that different serogroups may fall within the same ${ }^{35} \mathrm{~S}$-methionine group (strains typing as serogroup VI (lane 3) and III (lane 10) both type as $f$, and conversely, that the same serogroup may have different ${ }^{35} \mathrm{~S}$ - 


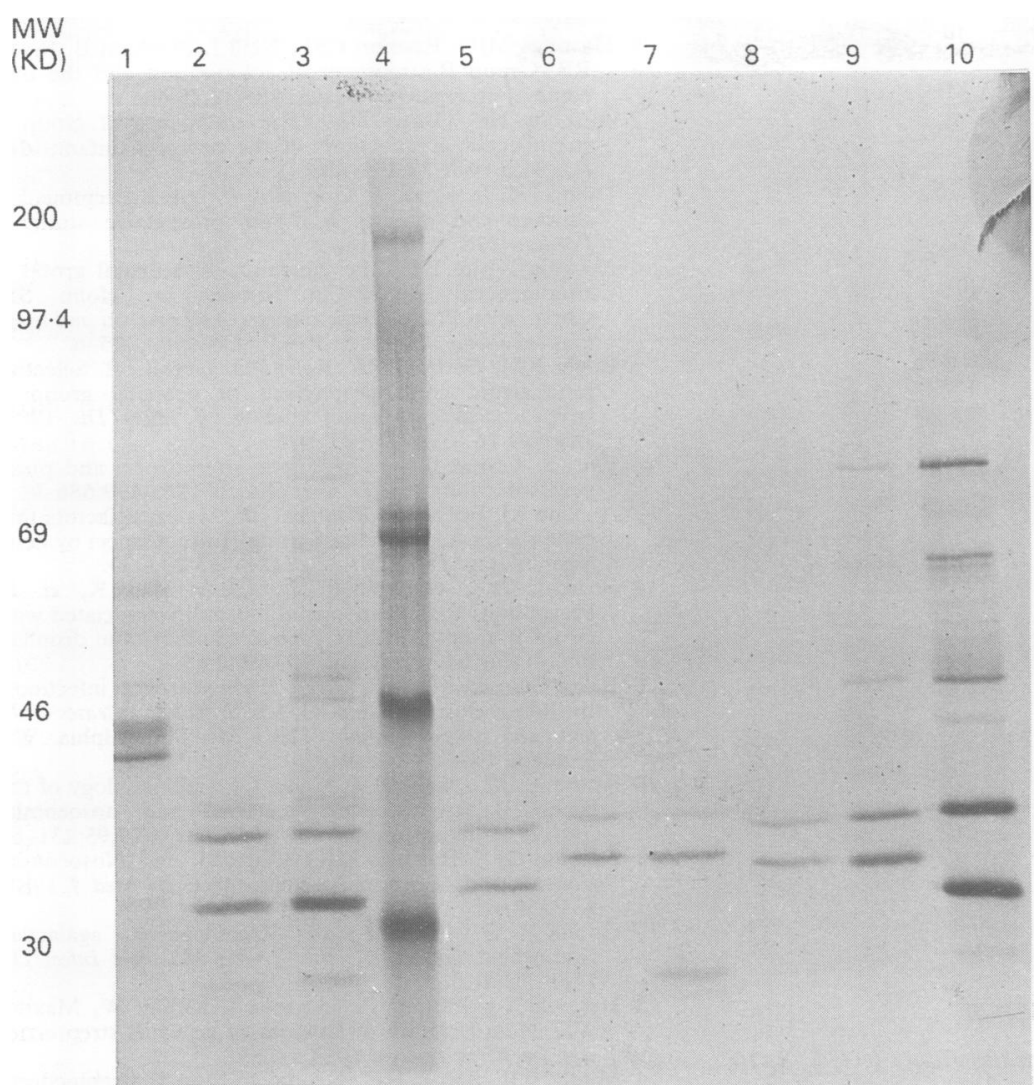

Figure 2 Autoradiographs of serotyped NCTC strains. Lane 1: type d; lane 2: NCTC 8182 (Ic), type f; lane 3: NCTC 8188(VI), type f; lane 4: molecular weight markers; lane 5: NCTC 8185 (III), type c; lane 6: type e; lane 7: NCTC 9993 (Ia), type e; lane 8: NCTC 8180 (Ib), type b; lane 9: NCTC 8100 (Ic), type b; lane 10: NCTC 8184 (III), type f. to take a small number of strains classified by existing systems and apply the new system to these as a means of assessment. ${ }^{23}$ Our view, however, is that a systematic approach of investigating a large number of clinical isolates should be undertaken to define a comprehensive typing system with the potential to use it for both epidemiological and analytical purposes.

In the case of group B streptococci, existing classifications are based on serotyping systems which identify type specific cell wall carbohydrate groups with some protein antigens, and on a defined phage typing system. ${ }^{24}$ Restriction endonuclease analysis (REA) has recently been performed on 54 isolates and seems to help in discriminate between serologically similar strains, but produced 28 different REA patterns. ${ }^{18} \mathrm{~A}$ second study noted two particular restriction digest patterns from nine of 10 strains of neonates with early onset disease. ${ }^{25}$ This methodology has not, however, been developed into a coherent typing system and its very complexity suggests that it would have limited use for this purpose.

As there is evidence that bacterial proteins are involved in the pathogenesis of invasive group B streptococci disease, a typing scheme which is based on protein analysis is appropriate. ${ }^{15}{ }^{35} \mathrm{~S}$-methionine analysis has been used for epidemiological purposes to investigate outbreaks, but only in the case of Clostridium difficile has the technique been used to develop a comprehensive typing scheme ${ }^{26}$ which has been applied clinically. ${ }^{27}$

Less than $10 \%$ of strains we tested could not be typed due to failure of incorporation of the ${ }^{35} \mathrm{~S}$-methionine. Group B streptococci grows better under anaerobic conditions and also produces both increased haemolysis and more of its characteristic tan pigment on starch medium if it is grown anaerobically. Initial difficulties with ${ }^{35} \mathrm{~S}$-methionine incorporation into the bacterial proteins were overcome by performing the incorporation under strict anaerobic conditions.

There was good discrimination among the groups with only $3 \%$ of strains not allocated to one of the seven identified groups. These are likely to form the basis for further extension and refinement of the system especially as it is applied over a wider geographical area. ${ }^{28}$ The system also allows for good reproducibility: the 73 strains which were typed on more than one occasion produced the same result. Reproducibility is more readily achieved by using appropriate controls on the typing gel. With the current complement of seven standard strains, seven standard strains, a molecular weight marker, and seven test strains can all be run on a single gel (fig 3). The strains analysed in this report have not been subject to serotyping because the basis of the serotyping system is the polysaccharide component of the organism. As anticipated, there was no relation between the serogroup and the ${ }^{35} \mathrm{~S}$-methionine group among the serotyped NCTC strains examined. In 35 additional strains which have been both serotyped and typed by the re- 


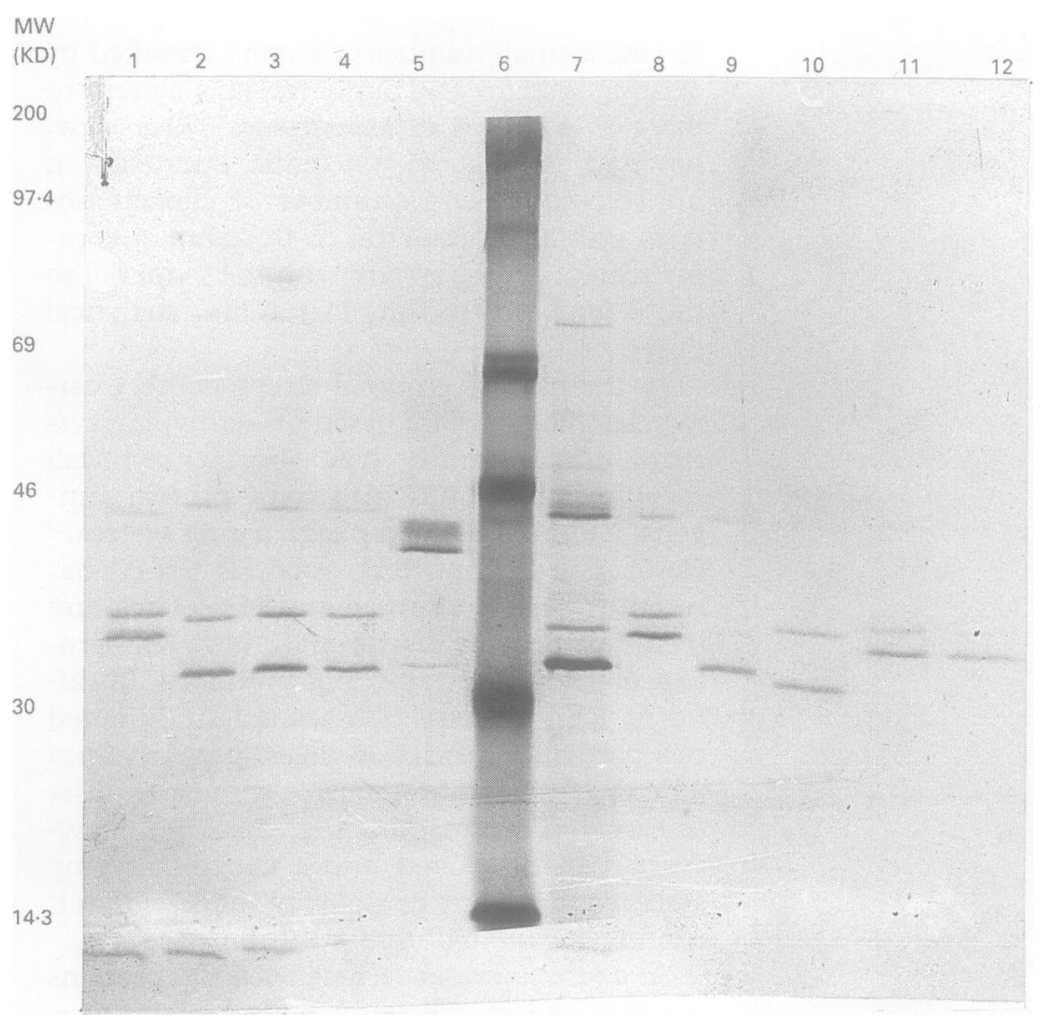

Figure 3 Autoradiographs of standard group B streptococci strains (lanes 1, 3, 5, 8, 10, 12) and test strains (lanes 2, 4, 7, 9, 11). Lane 1: type b; lanes 2-4: type c; lane 5: tupe d; lane 6: molecular weight markers; lanes 7 and 9: untypable; lane 8: type e; lane 10: type f; lanes 11 and 12: type g.
1 Hastings MJG, Easmon CSF, Neill J, Bloxham B, Rivers RP. Group B streptococcal colonization and the outcome of pregnancy. Infect 1986;12:23-9.

2 Anthony BF, Okada DM. The emergence of group B streptococci in infections of the newborn infant. Ann streptococci in infections
Rev Med 1977;28:355-69.

3 Dillon HC Jr, Khare S, Gray BM. Group B streptococcal carriage and disease: a 6 -year prospective study. $f$ Paediatr 1987;110:31-6.

4 Maynon-White RT. The incidence of neonatal group B streptococcal disease in Britain. In: Holm SE, Christensen P, eds. Basic concepts of streptococci and streptococcal disease. Chertsey: Reedbooks 1982;305-6.

5 Boyer KM, Gadzala CA, Kelly PD, Gotoff SP. Selective intrapartum chemoprophylaxis of neonatal group B streptococcal early-onset disease. $\mathcal{f}$ Infect Dis 1983; 148:810-16.

6 Faro S. Group B beta-hemolytic streptococci and puerperal infections. Am $\mathcal{f}$ Obstet Gynecol 1981;139:686-9.

7 Ancona RJ, Ferrieri P, Williams PP. Maternal factors that enhance the acquisition of group B streptococci by newborn infants. $\mathcal{F}$ Med Microbiol 1980;13:273-80.

8 Burman LG, Christensen P, Christensen K, et al. Prevention of excess neonatal morbidity associated with group B streptococci by vaginal chlorhexidine disinfection during labour. Lancet 1992;340:65-9.

9 Baker CJ, Edwards MS. Group B streptococcal infections. In: Remington JS, Klein JO, eds. Infectious diseases of the fetus and newborn infant. Third edn Philadelphia: WB fetus and newborm infant.

10 Anthony BF, Okada BM, Hobel CJ. Epidemiology of the group B streptococcus: maternal and nosocomial group B streptococcus: maternal and nosocomial
sources for infant acquisitions. $\mathcal{F}$ Pediatr 1979;95:431-6.

11 Easmon CSF, Hastings MJG, Clare AJ, et al. Nosocomial transmission of group B streptococci. Br Med $\mathcal{F} 1981$; 283:459-61.

12 Colman G. Typing of Streptococcus agalactiae (Lancefield Group B). Eur $\mathcal{f}$ Clin Microbiol Infect Dis 1988;7:226-31.

13 Henrichen J, Ferrieri P, Jelinkova J, Kohler W, Maxted WR. Nomenclature of antigens of group B streptococcus. Int $\mathcal{Y}$ Syst Bactyid 1984;34:500.

14 Milder CJJ, Aanen HC. Neonatal group B streptococcal meningitis. Arch Dis Child 1984;59:439-43.

15 Chun CSY, Brady LJ, Boyle MDP, Dillon HC, Ayout EM. Group B streptococcal C-protein associated antigens: association with neonatal sepsis. $\mathcal{F}$ Infect Dis 1991; 163:786-91.

16 Flores AE, Ferrieri P. Molecular species of R-protein produces by clinical isolates of group B streptococci. $\mathcal{f}$ Clin Microbiol 1989;27:1050-4.

17 Denning DW, Bressack M, Troup NJ, Tompkins LS. Infant with two relapses of group B streptococcal sepsis documented by DNA restriction enzyme analysis. Paediatr Infect Dis 1988;7:729-32.

18 Denning DW, Baker CJ, Troup NJ, Tompkins LS. Restriction endonuclease analysis of human and bovine Restriction endonuclease analysis of human and bovine group B streptococci for
Microbiol 1989;27:1352-6.

19 Feldman RG, Fleer A. The immune response to the group B streptococcus. Rev Med Microbiol 1992;3:52-8.

20 Lancefield RC, McCarty M, Everly WN. Multiple mouseprotective antibodies directed against group B streptococci. $\mathcal{E}$ Exp Med 1975;142:165-79.

21 Madoff LC, Michel JL, Kasper DL. A monoclonal antibody identifies a protective C-protein alpha-antigen epitope in group B streptococci. Infect Immun 1991:59: 204-10.

22 Poxton IR, Aronsson B, Molby R, Nord CE, Collee JG. Immunochemical fingerprinting of Clostridium difficile Immunochemical fingerprinting of Clostridium difficile colitis and diarrhoea. $7 \mathrm{Med}$ Microbiol 1984;17:317-24.

23 Cookson BD, Stapleton P, Ludlam H. Ribotyping of coagulase-negative staphylococci. $\mathcal{F}$ Med Microbiol 1992; 36:414-19.

24 Stringer J. The development of a phage-typing system for group B streptococci. ₹ Med Microbiol 1980;13:133-43.

25 Nagano $Y$, Nagano K, Takahashi S, et al. Restriction endonuclease digest patterns of chromosomal DNA from group B beta-haemolytic streptococci. $f \mathrm{Med}$ Microbiol 1991;35:297-303.

26 Tabaqchali S, O'Farrell S, Holland D, Silman R. Typing scheme for Clostridium difficile. Lancet 1984;ii:935-8.

27 Heard S, O'Farrell S, Holland D, Crook S, Barnett MJ, Tabaqchali $S$. The epidemiology of Clostridium difficile with use of a typing scheme: nosocomial acquisition and with use of a typing scheme: nosocomial acquisition and cross-infection among imm

28 Tabaqchali S. Epidemiologic markers of Clostridium difficile. Rev Infect Dis 1990;12(Suppl 2):S192-S9.

29 Broughton RA, Baker CJ. Role of adherence in the pathogenesis of neonatal group B streptococcal infection. Infect Immun 1983;39:837-43.

30 Hellerquist CG, Sundell H, Gettins P. Molecular basis for group B beta-haemolytic streptococcal disease. Proc Nat Acad Sci USA 1987;84:51-5. 